\title{
Outcome of restorative proctocolectomy when the diagnosis is suggestive of Crohn's disease
}

\author{
S P Grobler, K B Hosie, E Affie, H Thompson, M R B Keighley
}

\begin{abstract}
Twenty of 81 patients treated by restorative proctocolectomy for presumed ulcerative colitis had some features of Crohn's disease: 10 were classified as definite Crohn's disease and $\mathbf{1 0}$ as indeterminate colitis. These pathological features were first apparent during synchronous colectomy and pouch construction in 10 of 11 cases. In the remainder, histological features of possible Crohn's disease were first identified during rectal excision $(n=6)$, preliminary subtotal colectomy $(n=2)$, and after pouch excision $(=2)$. Complications were marginally more common in patients with features of possible Crohn's disease: pelvic sepsis 30\% (Crohn's disease $30 \%$, indeterminate colitis $30 \%$ ) $v 20 \%$, fistulas 45\% (Crohn's disease 30\%, indeterminate colitis $60 \%$ ) $v 16 \%$; ileal stenosis $40 \%$ (Crohn's disease $40 \%$, indeterminate colitis $40 \%$ ) $v 21 \%$, pouchitis $\mathbf{5 0 \%}$ (Crohn's disease $\mathbf{5 0 \%}$, indeterminate colitis $50 \%$ ) $v 26 \%$, and small bowel obstruction 25\% (Crohn's disease 30\%, indeterminate colitis $30 \%$ ) $v 13 \%$. Pouch excision or a persistent proximal stoma has been necessary in six patients with possible Crohn's disease (30\%) (Crohn's disease 3 cases $30 \%$, indeterminate colitis 3 cases $30 \%$ ) compared with nine $(15 \%)$ of the remainder. Median hospital stay, however, was the same and stool frequency in those with a functioning pouch were comparable. These results show that there is a higher complication rate if there are features of Crohn's disease but that the medium term functional results are acceptable if the pouch can be retained.

(Gut 1993; 34: 1384-1388)
\end{abstract}

Restorative protocolectomy with construction of an ileal pouch-anal anastomosis has an established role in the surgical management of ulcerative colitis. ${ }^{1-3}$ On the other hand, patients with Crohn's disease are generally regarded as unsuitable candidates for reservoir procedures because of the risk of recurrent ileal or anal disease, a higher incidence of postoperative fistula, poor functional results, and increased morbidity. ${ }^{46} \mathrm{~A}$

TABLE I Patient and operative details

\begin{tabular}{lcll}
\hline & $\begin{array}{l}\text { Definite } \\
\text { Crohn's } \\
\text { disease } \\
(n=10)\end{array}$ & $\begin{array}{l}\text { Indeterminate } \\
\text { colitis } \\
(n=10)\end{array}$ & $\begin{array}{l}\text { Ulcerative } \\
\text { colitis } \\
(n=61)\end{array}$ \\
Patients & $37(16-49)$ & $31(13-48)$ & $32(13-63)$ \\
\hline Median age (range) & $7: 3$ & $2: 8$ & $30: 31$ \\
Sex (m:f) & $3(30 \%)$ & $6(60 \%)$ & $36(59 \%)$ \\
Preliminary colectomy & $7(70 \%)$ & $4(40 \%)$ & $25(41 \%)$ \\
Synchronous colectomy and restorative proctocolectomy & $8: 2: 0$ & $7: 2: 1$ & $48: 9: 4$ \\
Pouch design(J:W:S) & $4(40 \%)$ & $4(40 \%)$ & $26(43 \%)$ \\
Totally stapled procedure & $6(60 \%)$ & $8(80 \%)$ & $38(59 \%)$ \\
Covering ileostomy & $68(36-100)$ & $70(33-105)$ & $67(34-126)$ \\
Median follow up (months) & & & \\
\hline
\end{tabular}

confident distinction between ulcerative colitis and Crohn's colitis is not possible in all patients despite adequate clinical and pathological evaluation and many are classified as having indeterminate colitis. ${ }^{78}$ The outcome in these patients is uncertain and the advisability of restorative proctocolectomy is, therefore, controversial. ${ }^{910}$

This study, based in one centre, has monitored the outcome of patients with various features of Crohn's disease who have had restorative proctocolectomy.

\section{Patients and methods}

Eighty one consecutive patients have had restorative proctocolectomy for inflammatory bowel disease between January 1983 and October 1990 under the care of one surgeon. All have been followed up for at least two years. Before operation all patients were regarded as having ulcerative colitis based on a combination of clinical, radiological, endoscopic, and pathological findings. At laparotomy none of the patients had macroscopic evidence of small bowel or perianal disease, and the colectomy specimens all showed macroscopic features of continuous colitis. All the available pathological material on these 81 patients was reviewed by one person with an international reputation in the pathology of inflammatory bowel disease $\mathrm{e}^{11}$ who did not know the outcome of the operation. Originally only four patients were classified as having definite Crohn's disease and 15 as indeterminate colitis leaving 62 with ulcerative colitis. After the material had been reviewed the final diagnosis was changed in $20(25 \%)$. All patients attend a regular follow up clinic, none have been lost to follow up but seven patients are contacted through local gastroenterologists either because they find travel to the centre difficult or because they now live abroad. This histopathological review divided patients into three groups: (a) definite Crohn's colitis $(n=10)$ because of the presence of non-causating epithelioid granulomas and microgranulomas; (b) indeterminate colitis $(n=10)$ because of features suggestive of Crohn's disease, but not sufficient to substantiate a firm diagnosis, such as transmural, focal or discontinuous disease, fissure ulcers, mural fibrosis or retention of goblet cell population; (c) definite ulcerative colitis $(n=61)$ with diffuse mucosal inflammation without granulomas affecting the rectum and some or all of the colon in continuity with the rectum. ${ }^{12}$

The clinical and functional outcome in the 20 patients with some features of Crohn's disease (definite Crohn's disease $n=10$; indeterminate colitis $n=10$ ) was compared with the remaining 61 patients with 'typical' ulcerative colitis. 
Statistical analysis

Comparisons of proportions were made by $\chi^{2}$ (with Yates's correction for small numbers) or Fisher's exact tests, and Wilcoxon's rank sum tests were used to examine differences in continuous variables such as age, follow up, and function. A probability of $<0.05$ was considered significant; $95 \%$ confidence intervals (CI) were calculated where appropriate.

\section{Results}

Patients in each of the three groups were comparable with respect to age and length of follow up. There were more men in the definite Crohn's group and women predominated in the indeterminate group (Table I). A preliminary colectomy was undertaken in nine of 20 patients with some features of Crohn's disease (45\%) (three in definite Crohn's disease; six in indeterminate colitis) compared with $59 \%$ with ulcerative colitis. The different techniques of pouch construction reflect the surgical developments on the unit with the totally stapled J-pouch-anal anastomosis being favoured in the latter part of the survey. ${ }^{13} \mathrm{~A}$ covering loop ileostomy was selectively omitted in low risk cases until September 1988, since then a clinical trial has been in progress in which patients were randomised to receive either an ileostomy or no ileostomy. ${ }^{14}$

\section{TIMING OF THE DIAGNOSIS}

Crohn's disease - three of 10 patients regarded as having definite Crohn's disease on histopathological review had had subtotal colectomy before restorative proctocolectomy (Table II). Two were for fulminant colitis, in one case Crohn's disease was subsequently identified in the proctectomy specimen and in the other Crohn's was recognised only in the ileal reservoir after excision. In the third colectomy specimen, there

TABLE II Timing and diagnosis

\begin{tabular}{llllll}
\hline & $\begin{array}{l}\text { Synchronous colectomy } \\
\text { and pouch construction }\end{array}$ & $\begin{array}{l}\text { Previous subtotal } \\
\text { colectomy } \\
\text { Pouch } \\
\text { excision }\end{array}$ & & $\begin{array}{l}\text { Subsequent rectal } \\
\text { excision }\end{array}$ & $\begin{array}{l}\text { Pouch } \\
\text { excision }\end{array}$ \\
\hline $\begin{array}{l}\text { Definite Crohn's } \\
\text { disease }(\mathrm{n}=10)\end{array}$ & $7: \rightarrow(7)$ & & $3:$ & (1) \\
\hline $\begin{array}{l}\text { Indeterminate } \\
\text { colitis }(\mathrm{n}=10)\end{array}$ & $4: \rightarrow(3)$ & $(1)$ & $6: \rightarrow(3)$ & $(3)$ \\
\hline
\end{tabular}

No having operation; ( ) No where diagnosis suggestive of Crohn's was made.

TABLE III Comparison of complications after restorative proctocolectomy

\begin{tabular}{llll}
\hline & $\begin{array}{l}\text { Definite Crohn's } \\
\text { disease } \\
(n=10)\end{array}$ & $\begin{array}{l}\text { Indeterminate } \\
\text { colitis } \\
(n=10)\end{array}$ & $\begin{array}{l}\text { Ulcerative } \\
\text { colitis } \\
(n=61)\end{array}$ \\
\hline Patients & $3(30 \%)$ & $6(30 \%)$ & $12(20 \%)$ \\
Pelvic sepsis & $3(30 \%)$ & $6(60 \%)^{\star}$ & $10(16 \%)$ \\
Fistulas - total no of patients with fistulas & $1+$ & 5 & 5 \\
Pouch vaginal or pouch perineal fistulas & $1+$ & 1 & 2 \\
Pouch cutaneous fistulas & $1+$ & $4(40 \%)$ & $13(21 \%)$ \\
Ileocutaneous (non-pouch) fistula & $4(40 \%)$ & $5(50 \%)$ & $16(26 \%)$ \\
Ileoanal stenosis & $5(50 \%)$ & 2 & $2(3 \%)$ \\
Pouchitis - all cases & $3^{\star}$ & $3(30 \%)$ & $8(13 \%)$ \\
Recurrent pouchitis & $2(20 \%)$ & &
\end{tabular}

${ }^{\star} \mathrm{p}<0.05$ ( $v$ ulcerative colitis: Fisher's exact test); $\dagger=$ same patient. were some features of possible Crohn's disease but the balance of evidence favoured ulcerative colitis; the subsequent proctectomy specimen confirmed the presence of granulomata and the diagnosis was changed to Crohn's disease. In the remaining seven patients the diagnosis was made after colectomy and synchronous pouch formation despite preoperative endoscopic biopsies suggesting ulcerative colitis.

Indeterminate colitis - six patients had a subtotal colectomy before diagnosis, three having had an ileorectal anastomosis and three an ileostomy with a retained rectal stump. In three, the diagnosis of indeterminate colitis was made from the colectomy specimen, whereas in the other three the diagnosis was only made after examination of the excised rectum (two after ileorectal anastomosis). Four patients with indeterminate colitis had a one stage restorative proctocolectomy; in three the diagnosis was made from the proctocolectomy specimen, but the other was only identified after pouch excision for refractory pouchitis.

\section{COMPLICATIONS (TABLE III)}

In patients with 'typical' ulcerative colitis pelvic sepsis occurred in $20 \%$ and postoperative fistulas in $16 \%$. These complications all occurred within three months of operation and all were considered to be technical in nature. Most complications $(n=7)$ occurred in the first third of the series and may partly be ascribed to a 'learning process' with the operation. Three exceptions to this pattern were low pouch vaginal or pouch perineal fistulas that developed 4-6 months after restorative proctocolectomy.

In the 10 patients with definite Crohn's colitis pelvic sepsis developed postoperatively in three patients and all three developed postoperative pouch related fistulas. One patient with pelvic sepsis developed a pouch-vaginal fistula and ileoanal stenosis culminating in pouch excision. Another patient with pelvic sepsis developed a pouch cutaneous fistula and was converted to a Kock continent reservoir but developed multiple, recurrent small bowel Crohn's fistulas and eventually required pouch excision. A third patient with pelvic sepsis had a partial dehiscence of the ileoanal anastomosis and a pouch vaginal fistula and was managed by diverting ileostomy. The pouch has now been excised. The initiating event in these three cases may have been technical, but the persistent fistulas are probably related to underlying Crohn's disease.

Of the 10 patients with indeterminate colitis three developed pelvic sepsis one because of a leak from the pouch and six have developed some form of pouch related fistula $(\mathrm{p}=0.01 v$ ulcerative colitis group). A single early pouch cutaneous fistula was the result of a partial ileoanal anastomotic dehiscence and pelvic sepsis; her postoperative treatment required multiple admissions for recurrent fistulation and bowel obstruction, but the fistula has been excised and she now has good pouch function. Five low pouch vaginal fistulas presented at a median of 24 months (range 6-48 months) after restorative proctocolectomy. Three pouch vaginal fistulas have been resolved by seton fistulotomy. 
Another patient with a low fistula has had her pouch excised and has been successfully converted to a Kock ileostomy because of severe ileoanal stenosis requiring pouch intubation that became socially unacceptable. The fifth patient with a pouch vaginal fistula also had repeated episodes of pouchitis unresponsive to metronidazole and steroids, and developed multiple superficial pouch perineal and pouch vaginal fistulas, which were managed by laying them open and a proximal diverting ileostomy; her ileostomy has now been closed and she has a good functional result.

Ileoanal stenosis occurred in four patients with definite Crohn's disease (40\%) compared with four with indeterminate colitis $(40 \%)$, and 13 with ulcerative colitis $(21 \%)$; these differences were not statistically significant.

Intestinal obstruction - episodes of small bowel obstruction occurred in two patients with definite Crohn's disease $(20 \%)$, in three with indeterminate colitis (30\%), and in eight (13\%) with ulcerative colitis.

Pouchitis developed in five (50\%) of the patients with definite Crohn's disease and in five (50\%) of those with indeterminate colitis compared with only $16(26 \%)$ in the ulcerative colitis group. Recurrent pouchitis or persistent pouchitis unresponsive to the customary course of metronidazole, occurred in three of five Crohn's patients and in two of five with indeterminate colitis compared with only two of 16 with ulcerative colitis. Of the three cases of Crohn's disease with recurrent pouchitis, one remains on longterm low dose maintenance metronidazole and two have required temporary pouch defunctioning by loop ileostomy but have now been closed.

Of the two patients with recurrent pouchitis who have indeterminate colitis, one remains on low dose maintenance metronidazole and one has had his pouch excised because of unacceptable functional results. Of the two patients with recurrent pouchitis who have ulcerative colitis both have had pouch excision because of poor functional results.

TABLE IV Comparison of outcome after restorative proctocolectomy

\begin{tabular}{lccc}
\hline & $\begin{array}{l}\text { Definite Crohn's } \\
\text { disease } \\
(n=10)\end{array}$ & $\begin{array}{l}\text { Indeterminate } \\
\text { colitis } \\
(n=10)\end{array}$ & $\begin{array}{l}\text { Ulcerative } \\
\text { colitis } \\
(n=61)\end{array}$ \\
\hline Patients & $6(60 \%)$ & $5(50 \%)$ & $26(43 \%)$ \\
Reoperation - all cases & $3(30 \%)$ & $4(40 \%)$ & $19(31 \%)$ \\
Reoperation - sepsis & $28(12-160)$ & $29(7-58)$ & $25(7-119)$ \\
Hospital stay (days) median (range) & $3(30 \%)$ & $3(30 \%)$ & $9(15 \%)$ \\
Failures - all cases & - & -5 & 1 \\
$\quad$ Primary stoma not closed & 3 & $3 \star$ & 8 \\
Pouch excision & &
\end{tabular}

^One patient with an ileoanal stenosis now converted to Kock continent ileostomy.

TABLE V Comparison of postoperative functional outcome

\begin{tabular}{|c|c|c|c|}
\hline Patients & $\begin{array}{l}\text { Definite } \\
\text { Crohn's } \\
\text { disease } \\
(n=10)\end{array}$ & $\begin{array}{l}\text { Indeterminate } \\
\text { colitis } \\
(n=10)\end{array}$ & $\begin{array}{l}\text { Ulcerative } \\
\text { colitis } \\
(n=61)\end{array}$ \\
\hline $\begin{array}{l}\text { Functioning pouch } \\
\text { Follow up after ileostomy closure: months (range) } \\
\text { Median daily stool frequency (range) } \\
\text { Minor soiling } \\
\text { Frank incontinence } \\
\text { Anti-diarrhoeal drugs }\end{array}$ & $\begin{array}{l}7(70 \%) \\
48(15-86) \\
6(4-15)^{\star} \\
2 \\
0 \\
4\end{array}$ & $\begin{array}{l}7(70 \%) \\
37(21-93) \\
6(5-7) \\
2 \\
0 \\
2\end{array}$ & $\begin{array}{l}52(85 \%) \\
44(12-91) \\
6(3-10) \\
6(12 \%) \\
1(2 \%) \\
17(32 \%)\end{array}$ \\
\hline
\end{tabular}

${ }^{\star} \mathrm{p}=0.06$ ( $v$ ulcerative colitis: Wilcoxon's unpaired rank sum analysis)
HOSPITAL STAY

Despite the higher complication and reoperation rates in the definite Crohn's and indeterminate groups, the total hospital stay did not differ significantly between the groups (Table IV).

\section{FAILURES}

Restorative proctocolectomy was considered to have failed if the pouch had been excised or an ileostomy had not been not closed. There were three failures (30\%) in the Crohn's group (all three were for pelvic sepsis and fistula) and a further three failures $(30 \%)$ in the indeterminate colitis group (one for fistula, one for recurrent pouchitis, and one because of incapacitating diarrhoea) compared with nine failures (15\%) in the ulcerative colitis patients (six for ischaemia, two for recurrent pouchitis, and one for poor functional results) (relative risk $2.03(96 \% \mathrm{CI}$ $0 \cdot 81$ to $5 \cdot 10)$ ).

\section{POUCH FUNCTION (TABLE V)}

The median follow up after ileostomy closure was comparable in the three groups. Seven patients with definite Crohn's disease, seven with indeterminate colitis and 52 with typical ulcerative colitis have a functioning pouch. High stool frequency, imperfect continence or the use of anti-diarrhoeal drugs was similar in all three groups. In particular the median frequency of defecation did not differ between the groups.

\section{Discussion}

The histopathological features that distinguish Crohn's disease from ulcerative colitis are well described. ${ }^{12}{ }^{15-17}$ Nevertheless, the two diseases share many common histopathological features and the discriminating characteristics may be ill defined. A confident distinction between the two disorders remains a taxonomic problem in 8$20 \%$ of specimens. ${ }^{7} 16$ 18-21

Typical radiological, endoscopic, and histological features of ulcerative colitis were present in 11 of 36 patients treated by synchronous colectomy in our series who eventually were found to have evidence of definite Crohn's disease $(n=7)$ or indeterminate colitis $(n=4)$. Although a staged procedure - that is, preliminary colectomy - may have reduced the risk of performing a restorative proctocolectomy on unidentified Crohn's disease patients, this policy was also unreliable as nine of 45 patients who had a previous colectomy eventually turned out to have definite Crohn's disease $(n=3)$ or indeterminate colitis $(n=6)$ despite careful review of the colectomy specimens. The defunctioned rectum is a further source of diagnostic confusion as mucosal granulomas and transmural inflammation are common findings particularly if the rectum has been defunctioned. ${ }^{22-24}$ In our series two cases of Crohn's disease (one with prior fulminant colitis) and three indeterminate colitis were diagnosed solely on the proctectomy specimen.

Fulminant colitis is a common cause of confusion, even in colectomy specimens, because of 
discontinuous and transmural inflammation. The term indeterminate colitis was originally proposed as a temporary histopathological category for such unclassified cases in fulminant disease $^{720}$ but has recently been used clinically for patients with inflammatory bowel disease in whom the nature of the underlying disease cannot be firmly established. ${ }^{8}$

In this report we have studied the natural history of 20 patients having restorative proctocolectomy where the possibility of Crohn's disease was considered. All our patients were regarded as having ulcerative colitis before pouch surgery, based on all available clinical, endoscopic, radiological, and pathological information and at laparotomy based on absence of anal and ileal disease and from the macroscopic appearances of the resected bowel. The high rate of diagnostic revision (25\%) based on this independent, blind histopathological review may have overdiagnosed definite Crohn's disease but in many the final diagnosis was uncertain and labelled as indeterminate colitis. Most of the revisions were based, however, on resection specimens rather than from postoperative pouch biopsies, which may be difficult to interpret in patients with chronic pouchitis. ${ }^{25-27}$ Furthermore half of the patients with some features of Crohn's disease have been labelled as indeterminate colitis because the pathological features were not entirely diagnostic.

Despite careful selection, many centres with a large experience of restorative proctocolectomy now report a small number of patients who turn out to have Crohn's disease. ${ }^{28-32}$

The results of restorative proctocolectomy have generally been unfavourable if Crohn's disease is diagnosed as there is a high incidence of complications and the failure rate is unacceptable. Despite a relatively short term median follow up $(5.7$ years) only three of 10 patients (30\%) with definite Crohn's colitis have so far had their pouch excised, admittedly all were for fistulas, while the remaining seven have satisfactory function despite episodes of recurrent pouchitis in three. This compares with a small bowel resection rate of only $4 \%$ at five years among 116 patients having a proctocolectomy for Crohn's colitis in this unit. ${ }^{33}$ It may be very difficult to distinguish Crohn's disease from recurrent pouchitis, nevertheless typical small bowel recurrence has become apparent in all three patients who have had their pouch excised and in one other case in this series.

Longterm studies of the natural history of indeterminate colitis have suggested that most of these cases behave more like ulcerative colitis than Crohn's disease..$^{1021}$ In the study reported by Pezim and others, ${ }^{9} 5 \%$ of patients having a pouch procedure were identified as having indeterminant colitis. There was no significant increased complication rate or disturbed pouch function in those with indeterminate colitis. On the contrary, Koltun et $a l^{10}$ concluded that a diagnosis of indeterminate colitis predisposed patients having restorative proctocolectomy to an increased risk of perineal complications and pouch failure. Our study also found that pouch vaginal fistulas and pouchitis were common in this group. Nevertheless, the pouch operation failed in only three patients, the other seven having satisfactory functional results.

We believe that restorative proctocolectomy should not be advised for Crohn's disease and that if there are features suspicious of the disease, a preliminary colectomy should be advised. Patients should be warned, however, that a preliminary colectomy does not absolutely exclude the fact that they could eventually prove to have Crohn's disease. Inevitably patients with Crohn's disease or indeterminate colitis will from time to time have restorative proctocolectomy. Although some patients may develop serious complications such as fistulas, pelvic sepsis, pouchitis, and strictures the outcome in these patients is not necessarily a catastrophe and some enjoy remarkably satisfactory pouch function at least in the medium term.

S P Grobler is a Research Fellow supported by the University of the Orange Free State, Bloemfontein, Republic of South Africa. This paper has been presented in part to the following societies: This paper has been presented in part to the following societies:
Surgical Research Society, London, 3-4 January 1991. Short Surgical Research Society, London, 3-4 January 1991. Short paper meeting, Section of Coloproctology, Royal Society of surgery (Royal Society of Medicine and Surgical University Clinic , Vienna), Vienna, Austria, 2-3 May 1991. International GastroSurgical Club, European Digestive Disease Week, Amsterdam, The Netherlands, 20-26 October 1991.

1 Nicholls RJ. Restorative proctocolectomy with various types of reservoir. World F Surg 1987; 11: 751-62.

2 Dozois RR, Kelly KA, Welling DR. Ileal pouch-anal anastomosis: comparison of results in familial adenomatous anastomosis: comparison of results in familial adenomatous polyposis

3 Williams NS. Restorative proctocolectomy is the first choice elective surgical treatment for ulcerative colitis. Dr $\mathcal{F}$ Surg 1989; 76: 1109-10.

4 Halvorsen JF, Heimann P, Hoel R, Nygaard K. The continent reservoir ileostomy: review of a collective series of thirty-six patients from three surgical departments. Surgery 1978; 83: 252-8.

5 Dozois RR, Kelly KA, Beart RW Jr, Beahrs OH. Improved results with continent ileostomy. Ann Surg 1980; 192: 31924.

6 Dozois RR, Goldberg SM, Rothernberger DA, Utsonomiya J, Hyogo RJ, et al. Restorative proctocolectomy with ileal Hyogo RJ, et al. Restorative proctocolect.

7 Price AB. Overlap in the spectrum of non-specific inflammatory bowel disease - 'colitis indeterminate'. 7 Clin Pathol 1978; 31: 567-77.

8 Tanaka $M$, Riddell RH. The pathological diagnosis and differential diagnosis of Crohn's disease. Hepatogastroenterology 1990; 37: 18-31.

9 Pezim ME, Pemberton JH, Beart RW Jr, Wolff BG, Dozois RR, Nivatvongs $S$, et al. Outcome of 'indeterminant' colitis following ileal pouch-anal anastomosis. Dis Colon Rectum 1989; 32: 653-8.

10 Koltun WA, Schoetz DJ Jr, Roberts PL, Murray JJ, Coller $\mathrm{JA}$, Veidenheimer MC. Indeterminate colitis predisposes to perineal complications after ileal pouch-anal anastomosis. Dis Colon Rectum 1991; 34: 857-60.

11 Thompson H. Histopathology of Crohn's disease. In: Allan RN, Keighley MRB, Alexander-Williams J, Hawkins CF, RN, Keighley MRB, Alexander-Williams J, Hawkins CF, eds. Inflammatory bowel disease. 2 .

12 Morson BC, Dawson IMP. Inflammatory disorders. In: Morson and Dawson's gastrointestinal pathology. 3rd Ed. Oxford: Blackwell Scientific, 1990: 514-6.

13 Kmiot WA, Keighley MRB. Totally stapled abdomina restorative proctocolectomy. Br F Surg 1989; 76: 961-4.

14 Grobler SP, Hosie KB, Keighley MRB. Randomised trial of loop ileostomy in restorative proctocolectomy. $\mathrm{Br} \mathcal{F}$ Surg 1992; 79: 903-6.

15 Hamilton SR, Morson BC. Ulcerative colitis - pathology. Berk JE, ed. In: Bockus Gastroenterology. Vol 4. 4th Ed. Philadelphia: WB Saunders, 1985: 2139-46.

16 Hamilton SR. The differential diagnosis of idiopathic inflam matory bowel disease by colorectal biopsy. Int $\mathcal{F}$ Colorectal Dis 1987; 2: 113-7.

17 Lennard-Jones JE. Classification of inflammatory bowel disease. In: Shivananda S, Hordink ML, Pena AS disease. In: Shivananda S, Hordink ML, Pena AS, first European Community workshop on inflammatory bowel disease. Scand 7 Gastroenterol 1989; 24 (suppl 170): $2-6$.

18 Jones JH, Lennard-Jones JE, Morson BC. Numerical taxonomy and discriminant analysis applied to non-specific colitis. Qf Med 1973; 168: 715-32.

19 Whitehead R. Ulcerative colitis, Crohn's colitis, ischaemic colitis, pseudomembranous colitis and antibiotic-associated colitis. In: Mucosal biopsy of the gastrointestinal tract. 4th Ed. Philadelphia: WB Saunders, 1990: 290-341. 
20 Lee KS, Medline A, Shockey S. Indeterminate colitis in the spectrum of inflammatory bowel disease. Arch Pathol Lab Med 1979; 103: 173-6.

21 Wells AD, McMillan I, Price AB, Ritchie JK, Nicholls RJ. Natural history of indeterminate colitis. BrF Surg 1991; 78: 179-81.

22 Whitehead R. Colitis: problems in definition and diagnosis. Virchows Arch [A] 1990; 417: 187-90.

23 Shepherd NA. Pathological mimics of chronic inflammatory bowel disease 7 Clin Pathol 1991; 44: 726-33.

24 Warren BF, Shepherd NA, Bartolo DC, Bradfield JWB. Histological changes of the defunctioned rectum in ulcerative colitis. F Pathol 1991; 63: 69A.

25 Warren BF, Shepherd NA. The role of pathology in pelvic ileal reservoir surgery. Int $\mathcal{f}$ Colorectal Dis 1992; 7: 68-75.

26 Levin KE, Pemberton JH, Phillips SF, Zinsmeister AR, Pezim ME. Role of oxygen free radicals in the etiology of pouchitis. Dis Colon Rectum 1992; 35: 452-6.

27 Rauh SM, Schoetz DJ, Roberts PL, Murray JJ, Coller JA, Veidenheimer MC. Pouchitis - Is it a wastebasket diagnosis? Dis Colon Rectum 1991; 34: 685-9.
28 Rothenberger DA, Long WD, Buls JG, Goldberg SM Christenson CE. Restorative proctocolectomy with ilea reservoir and ileoanal anastomosis for UC and familia polyposis. Dig Surg 1984; 1: 19-26.

29 Nicholls RJ, Pescatori M, Motson RW, Pezim ME. Restorative proctocolectomy with a three loop ileal reservoir for UC and familial adenomatous polyposis. Ann Surg 1984; 199: 383-8.

30 Dozois RR, Ileal 'J' pouch - anal anastomosis. Br 7 Surg 1985; 72 (suppl): S80-2.

31 Deutsch AA, McLeod RS, Cullen J, Cohen Z. Results of the pelvic-pouch procedure in patients with Crohn's disease. Dis

32 Hyman NH, Fazio VW, Tuckson WB, Lavery IC. Consequences of ileal pouch-anal anastomosis for Crohn's colitis. Dis Colon Rectum 1991; 34: 653-7.

33 Scammell B, Ambrose NS, Alexander-Williams I, Allan RN, Keighley MRB. Recurrent small bowel Crohn's disease is more frequent after subtotal colectom anastomosis than proctocolectomy. Dis Colon Rectum 1985 28: $770-1$. 